\title{
Proppants Categories for Hydraulic Fracturing Process of Petroleum Wells: A Review
}

\author{
AM Fadl* and MI Abdou \\ Egyptian Petroleum Research Institute (EPRI), Egypt
}

*Corresponding author: AM Fadl, Egyptian Petroleum Research Institute (EPRI),

Nasr city, Cairo, Egypt.

Received Date: April 05, 2019

Published Date: May 10, 2019

\begin{abstract}
Proppant is a gritty material with uniformly sized particles that is mixed in with fracturing fluid during the hydraulic fracturing (fracking) process to hold open fractures made in the ground. There are a variety of different types of proppant, including naturally occurring sand and manmade proppants. Man-made proppants include materials such as resin-coated sand or strong ceramic materials. Proppants come in a variety of different sizes and spherical shapes for a variety of different situations. Recently, demand for proppants has increased as oil and natural gas wells are being made to yield more oil and gas using hydraulic fracturing. One job can require a few thousand tons of this proppant material. There are several different types of materials used as proppant such as natural processed frac sand, resin-coated sand and ceramic proppants. Resin-coated sand is simply sand that is coated in a resin material to smooth the surface of the sand and make the shape more uniform. Coating the sand in resin increases its strength, making it more desirable as a proppant. Finally, ceramic proppants are the most uniform in shape and the strongest of the proppants as their manufacturing is entirely controlled. The uniform shape of this type of proppant ensures that there is more space for the oil and gas to flow through the proppant material and out of the well. Proppants come in a variety of different grain sizes, as well as different shapes. The size and shape of a proppant is important as it influences the final permeability in the induced fracture.
\end{abstract}

Keywords: Hydraulic fracturing; Oil and gas production; Hydraulic liquid; Proppant

\section{Introduction}

A proppant is a solid material, typically sand, treated sand or man-made ceramic materials, designed to keep an induced hydraulic fracture open, during or following a fracturing treatment. It is added to a fracking fluid which may vary in composition depending on the type of fracturing used, and can be gel, foam or slick water-based. In addition, there may be unconventional fracking fluids. Smallermesh proppants overtake large-mesh proppants in permeability after a certain threshold stress because it will mechanically fail (i.e. get crushed) and produce very fine particulates ("fines") at high closure stresses [1]. Though sand is a common proppant, untreated sand is prone to significant fines generation; fines generation is often measured in wt $\%$ of initial feed. A commercial newsletter from Momentive cites untreated sand fines production to be $23.9 \%$ compared with $8.2 \%$ for lightweight ceramic and $0.5 \%$ for their product [2]. Proppant geometry is also important; certain shapes or forms amplify stress on proppant particles making them especially vulnerable to crushing (a sharp discontinuity can classically allow infinite stresses in linear elastic materials) [3].

\section{Proppant Types and Properties}

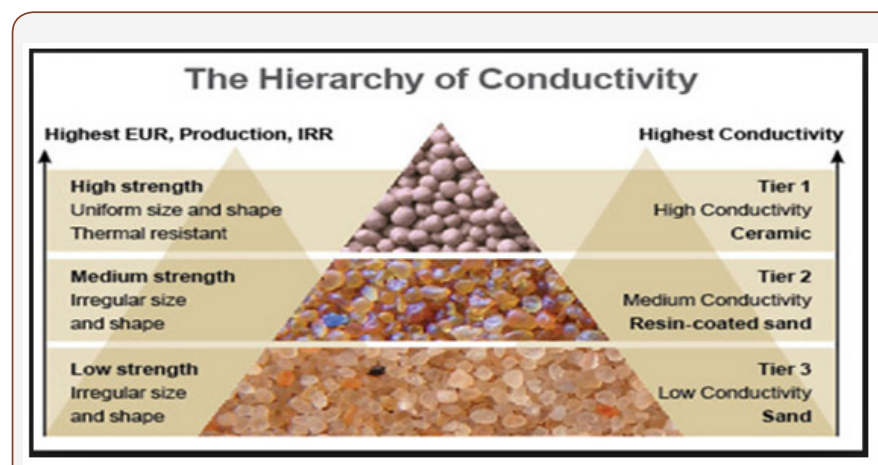

Figure 1: Proppant types pyramid.

Proppants materials can be grouped into three main categories as shown in Figure 1 \& Figure 2 rounded silica sand, gravel and resin coated sands, sintered and/or fused synthetic ceramic materials [4]. The most commonly used materials are sand, ceramic, sandlined resin and sintered bauxite [5,6]. Over the past six decades, 
materials such as walnut shell, Brandy and Ottawa sand, glass, kaolin and molten zirconia have been used as proppants [7]. Walnut shell, steel shot, aluminosilicates, molten zirconia, plastic pellets, glass beads, aluminum pellets and ash are also used and tested [8]. There are several types of proppants with different characteristics according to standard classification. These characteristics must be appropriate to the type of well and reservoir in order to be hydraulically fractured. Proppants act correctly in the support of opened cracks from fracking operation.

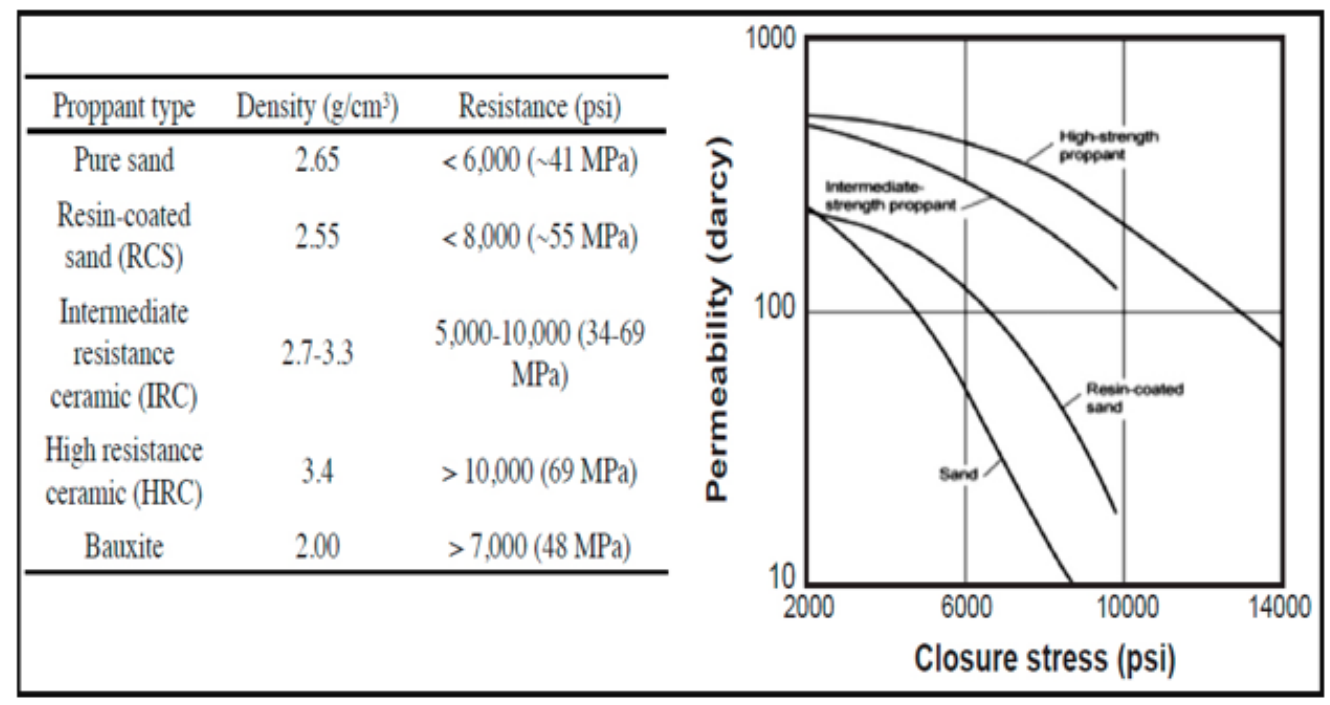

Figure 2: illustrates a scheme of the choice of proppant material according to the tension of fracture closure $[9,10]$.

\section{Acknowledgement}

None.

\section{Conflict of Interest}

No conflict of interest.

\section{References}

1. (2012) Physical Properties of Proppants. CarboCeramics Topical Reference, CarboCeramics, Archived from the original on 18 January 2013.

2. (2010) Critical Proppant Selection Factors. Fracline, Hexion.

3. Guimaraes MS, JR Valdes, AM Palomino, JC Santamarina (2007) Aggregate production: Fines generation during rock crushing. Journal of Mineral Processing 81(4): 237-247.
4. D Droppert, P Fiore, Y Dessureault, F Cardarelli (2002) High strength, heat- and corrosion-resistant ceramic granules for proppants.

5. K Mc Lin, D Brinton, P Mandalaparty, C Jones, J Moore (2010) Trans Geotherm. Resour Counc 1(34): 365.

6. F Liang, M Sayeda, GA Al Muntasheria, FF Chang, L Lia (2016) Petroleum 2(1): 1-26.

7. JR Hellmann, BE Scheetz, WG Luscher, DG Hartwich, RP Koseski (2014) Am Ceram Soc Bull 93(1): 1-29.

8. M O Driscoll, I Clarke (2015) in Proc SME Ann Conf Expo - CMA $117^{\text {th }}$ Nat West Min Conf, Colorado, USA.

9. J Kullman (2011) The complicated world of proppant selection. South Dakkota Sch Mines Techn, Dakota.

10. GFBL Silva (2011) in Proc. 55 Congr Brasil Cerâm, Porto de Galinhas, PE, Brasil. 